\title{
Variações entoacionais na língua portuguesa falada por idosos Guatós e não indios ${ }^{13}$
}

Natalina Costa

\section{Introdução}

O Pantanal Mato-grossense situa-se no centro da América do Sul, na Bacia do Alto Paraguai e sua extensão, estimada por Adamoli (1982) e Garcia (1984) é de aproximadamente 139.111 $\mathrm{km}^{2}$ (OLIVEIRA apud GARCIA, 1984, p. 15).

Nessa região, quase fronteira com a Bolívia, encontra-se a comunidade indígena denominada Guató, e os outros dois grupos de informantes que constitui nosso objeto de análise, a qual será destacada nessa pesquisa. Alguns índios Guató moram na aldeia Uberaba que se localiza em uma ilha fluvial, no Canal D. Pedro II, a Ilha Ínsua, e, nela, está localizado o II Batalhão de Fronteira do Exército Brasileiro, conhecida como Bela Vista do Norte, localizada no ponto extremo do Mato Grosso do Sul, município de Corumbá; outros, vivem na cidade de CorumbáMS.

\section{Antecedente e Justificativa}

Em se tratando da língua Guató, esta foi documentada pela primeira vez por Castelnau (1851), fazendo parte do tronco linguístico Macro-Jê. Atualmente, são poucos os seus falantes,

\footnotetext{
${ }^{13}$ ENCONTRO DE PÓS-GRADUANDOS DA FFLCH/USP - EPOG, 4. São Paulo, 2009.
} 
tendo em vista que a maioria dos falantes da comunidade, em destaque, fala só o português. Diante disso, surgiu a necessidade de se descrever as variações entoacionais da língua portuguesa, considerando a hipótese de fo como uma série temporal, formada pelas componentes Finalização $(F)$, Sustentação (S), e Foco/ênfase (E), e partindo da análise e da decomposição automática de f0, pelo aplicativos ExProsódia.

Assim, há o pressuposto de que variações prosódicas ocorrem, na fala, em língua portuguesa, desta comunidade indígena.

\section{Objetivos Gerais e Específicos}

Esta pesquisa teve como objetivo geral, a investigação, o documentário e dentro da proposta, um estudo que revele, por meio de depoimentos de vida e de uma pesquisa sócio-cultural, o modo como o grupo étnico Guató enxerga o mundo, hoje, para que futuramente deixemos algo escrito sobre esta comunidade.

Esta pesquisa tem como objetivo específico: A- Descrever a entoação da língua portuguesa falada por uma categoria de índios Guató, e duas categorias de não índios, considerando a hipótese de fo como uma série temporal, formada pelas componentes Finalização (F), Sustentação (S) e Foco/ênfase (E), e partindo da análise e da decomposição automática de f0, pelo aplicativo ExProsódia. B- Verificar a emanência da prosódia da língua materna na segunda língua, dos Guatós, mesmo depois de muito convívio com os não índios.

\section{Metodologia}

Como era de se esperar, em relação aos índios Guató, nosso primeiro contato foi muito difícil pois, mesmo dizendo que nosso objetivo era conhecer e estudar a história da região, bem como obter informações a respeito da experiência de vida dessa tribo, não conseguimos, de imediato, obter a confiança da 
comunidade. Por isso, foram necessárias outras visitas da pesquisadora, juntamente com pessoas influentes, pois para que pudéssemos coletar um material linguístico de boa qualidade, foi necessário fazer-se conhecer e conhecer a comunidade em que iríamos trabalhar e interagirmos com a família e com o grupo.

O primeiro contato feito com os Guató, a fim de obter informações orais foi em julho de 2006, inicialmente com as lideranças Severo Ferreira e sua esposa Dalva Ferreira, em Corumbá. A partir do contato com essas lideranças, e no mesmo período, foi feito contato com vários outros residentes em Corumbá, em sua maioria já incorporados na massa de proletários e subdesempregados. Dessa forma, no que se refere à seleção dos informantes, não tivemos muita escolha, se deu de imediato e de acordo com um requisito fundamental, a qualidade de falante original. Isto porque se observou que os Guató que dominam sua língua original são geralmente com idade igual ou superior a cinquenta anos Vale dizer que são os que mais conhecem a cultura tradicional do grupo. pois a língua guató está seriamente ameaçada de extinção. Nossas entrevistas ocorreram entre os meses de janeiro a outubro de 2008

Para que pudéssemos realizar as gravações das narrativas, em Corumbá pedimos o consentimento do Sr. Severo (o cacique), de D. Francolina, mais conhecida por Negrinha.

Para obtermos uma pesquisa com mais eficiência, fizemos várias visitas e nem sempre conseguíamos gravar as narrativas, pois não sabemos se proposital ou não as entrevistadas desviavam o assunto, por isso nossas narrativas aconteceram do mês de janeiro a outubro de 2008 e foram feitas por meio de gravações de produções de fala realizadas em trabalho de campo. 
As gravações de fala espontânea foram feitas com cinco sujeitos Guató, cinco sujeitos não indios na faixa etária de 30 a 45 anos e cinco na faixa etária de 46 a 60 anos. Esperamos que a partir desses quinze sujeitos possamos analisar no final 150 arquivos de fala dessa comunidade natural da região do Pantanal e os descendentes de Guatós. As gravações contêm pelo menos quinze minutos de fala espontânea, preconizando-se principalmente narrativas de caráter pessoal e individual, tendo em vista a natureza dos dados, toda a entrevista foi gravada, incluindo a participação do pesquisador.

As gravações foram feitas com gravador Panasonic, Digital transcriber, foram armazenadas em memória flash gravados em formato wave e descarregados em computador. Os dados foram segmentados pelo aplicativo Adobe Audition 2.0 da Adobe, e foram analisados pelo programa Speech Filing System, pois teria que ser um que aceitasse a análise prosódica e espectrográfica de grandes unidades sonoras e convertesse os resultados em arquivos de texto para a manipulação estatística automática.

Nesta pesquisa, estabelecemos os padrões de avaliação acústica nas gravações, pois o propósito foi submetê-las todas à rotina de análise automática ExProsódia. O processo de análise envolveu a manipulação de uma gama bastante grande de aplicativos de análise acústica para segmentar, converter e transcrever os arquivos, além fazer a conversão para a análise final de 150 arquivos de fala tomados a partir de quinze sujeitos, todos eles naturais na região do Pantanal e descendentes de Guatós, como já citados acima.

\section{O Contexto de Pesquisa}

O Estado de Mato Grosso do Sul é repleto de influências culturais oriundas de diversos lugares, não só de outras regiões do Brasil, como também de outros países, por tratar-se de um 
estado com uma extensa área de fronteira seca com países como, Paraguai e Bolívia e ainda, por sermos responsáveis por grande parte da produção agrícola do país, bem como a posição de maior produtor de carne bovina, fator que atrai para nossa região muitas pessoas vindas de outros estados, inclusive de outros países.

A formação do atual estado de Mato Grosso do Sul se deu com o povoamento e colonização, em conjunto com os grupos indígenas que habitavam a região e eram senhores absolutos das terras, sendo estes formados pelos povos: Guarani, com dois sub grupos: Ñandeva e Kayowá, Aruak representados pelos Terena, os Guaicurus representados pelos Kadiwel e os Kinikinawa, os Guató, os Ofayé, os Caipós e os Boróros, cujos descendentes ainda podem ser encontrados em reservas indígenas ou até mesmo perambulando pelo território onde tentam encontrar um espaço para sua sobrevivência..

Segundo o Censo 2.000 do IBGE - Instituto Brasileiro de Geografia e Estatística-a população indígena de Mato Grosso do Sul, cresceu $84,8 \%$ nos últimos dez anos.

Os Guató, objeto de nossa pesquisa constituem um grupo étnico diretamente ligado ao tronco linguístico Macro-Jê e estão fixados no Pantanal há muitos anos, ficaram conhecidos como índios canoeiros.

É importante ressaltar, que dos poucos índios que ainda falam o idioma Guató, dois moram no morro do Caracará: D. Júlia, a mais idosa, está cega, não fala e nem entende português e Vicente, um indígena de 55 anos, filho de D. Júlia.

Atualmente, a aldeia é coordenada por um cacique cujo nome é Severo. Este dá total apoio a todas as famílias residentes na aldeia, sendo o representante da tribo junto à FUNAI. Por outro lado, muitos índios contavam com D. Francolina, (in memorium) 
pois era a mais idosa e experiente índia da comunidade, além ser a única, em Corumbá, que falava a língua guató.

\section{Entoação}

Os trabalhos de Patricia Kuhl e seus colegas (KUHL; IVERSON, 1995; KUHL, 2000; KUHL et al., 2001), a partir de seu modelo de perceptual magnet effect (PME), pressupõem a existência de uma forma prototípica fixa, não abstrata, que atue como parâmetro de comparação inicial para todas as demais formas que venham ser percebidas. Essa proposta de análise traz à tona também o princípio de que os elementos iniciais da aquisição da linguagem serão tomados como formas prototípicas fixas e de que corresponderão a extremos dessas realizações.

A adequação do modelo far-se-á no sentido de se estabelecer que o reconhecimento de tons prosódicos está sujeito também à formação de categorias fundadas em um modelo específico, localizado nos extremos máximos das possibilidades de variação do fenômeno. Nesse caso, imaginar-se-ão que dois tons específicos graves e agudos serão as variações extremas de um tom médio, estabelecendo uma triangulação semelhante àquela do espaço vocálico, definidor das vogais cardinais /i, a, u/. Essa concepção que toma a elaboração de dois elementos extremos a partir de um elemento medial respalda-se na proposta feita por Chomsky e Halle (1968, doravante SPE), no que diz respeito, por exemplo, à diferenciação entre vogais altas e baixas, para as quais eles estabelecem a matriz: $\left[\begin{array}{c}+ \text { high } \\ - \text { low }\end{array}\right]$ para vogais altas, $\left[\begin{array}{l}- \text { high } \\ + \text { low }\end{array}\right]$ para vogais baixas e, finalmente, $\left[\begin{array}{l}-h i g h \\ -l o w\end{array}\right]$ para vogais médias. Na medida em que não há como se imaginar que a matriz com ambos os traços positivos possa ocorrer - 
$\left[\begin{array}{l}+ \text { high } \\ + \text { low }\end{array}\right]$ - pois um segmento está impedido de ser alto e baixo simultaneamente, podemos imaginar que a concepção matricial proposta no SPE equivalha à triangulação gráfica que entendemos representar melhor o estabelecimento de formas prototípicas definidas a partir de um valor básico.

Se estabelecermos as dimensões de grave e agudo no eixo das abscissas $x$ e a distribuição de frequências no eixo das ordenadas $y$ teremos:



Figura 1. Variação da entoação por variação de frequência. As linhas pontilhadas escuras mostram o ponto médio de cada banda e as linhas contínuas escuras os limites de 3st de variação tonal não significativa da fala (T'HART, 1981)

$\mathrm{Na}$ fala, entretanto, principalmente desta comunidade indígena Guató, em que as variações excedem facilmente os limites das variações, dificilmente se poderá fazer pelo exame da trajetória 
ou por seus pontos de chegada, na medida em que oscilações muito grandes poderão ocorrer.

Nesse caso, a análise automatizada da fala espontânea, bem como a abordagem experimental por meio da manipulação dos dados, é imprescindível. A diversidade da fala espontânea e a não espontânea que iremos buscar com a comunidade indígena Guató e as outras duas categorias têm de ser objeto de análise na medida em que a entoação parece ser dependente da programação feita pelos nossos falantes de suas produções de fala.

Tendo em vista a pesquisa tratar de uma análise da prosódia segundo os princípios básicos da análise musical, tem-se a hipótese de que as idiossincrasias culturais manifestas na tradição musical de um povo refletem-se na prosódia (GLASER, 2000; SCHELLENBERG; TREH, 1999). Dessa maneira, o controle dessas variáveis, num projeto dessa natureza, faz-se necessário. Tanto as variações étnicas, quanto à variação linguística são importantes nesse caso.

\section{Resultado da pesquisa}

Nesta pesquisa percebemos na fala das senhoras Guató que ainda sobram resíduos da prosódia da fala Guató, mesmo residindo em Corumbá-MS há muito tempo e os mais velhos têm a prosódia difundida do falante português que têm a mesma idade. Na cadeia segmental existe a característica do português regional da fala do português.

Do conjunto de cento e cincoenta (150) frases analisadas, extraímos os tons médios, TM, e os tons finais, TF de cada uma, por meio da rotina de análise automática ExProsódia. Conforme se pode verificar nas tabelas e gráfico abaixo, a sequência observada em semitons, convertidos em valores MIDI . 
Ao fazer a análise das tabelas e gráfico vimos que o $\mathrm{P}<0,05$, e que o $\mathrm{F}$ esperado é menor do que o $\mathrm{F}$ obtido e que por isso as comparações apontaram diferenças significativas entre os 3 grupos de sujeitos analisados.



\section{Conclusão}

Conforme as análises que se apresentaram acima, verificamos que a fala das senhoras guatós e a das senhoras corumbaenses mantêm como característica o fato de que as finalizações ocorrem em tom muito próximo ao da finalização. Verificamos também que a fala das senhoras guatós mantém como característica as finalizações e os tons médios ocorrem em tom mais grave do que a das senhoras e moças corumbaenses. Dessa maneira, podemos caracterizar a fala das senhoras guatós pela presença simultânea de tom médio com finalização grave e pela proximidade tonal entre finalização e tom médio" 